\title{
Distribution of health-related physical fitness in Slovak population
}

\author{
Viera Bebcakova', Bibiana Vadasova' ${ }^{1}$, Peter Kacur ${ }^{1}$, Jan Junger ${ }^{1}$, Iveta Borzikova' ${ }^{1}$, Martin Zvonar² \\ and Marta Gimunova ${ }^{2^{*}}$
}

\begin{abstract}
Purpose of the study was to examine relationship between distribution of healthy fitness zone standards of high school students and their type of housing or area of residence. Study sample consisted of 684 students (284 boys, 400 girls) from urban and rural areas of the region Presov in the eastern part of Slovakia. Physical fitness was assessed by four tests: back-saver sit and reach, shoulder stretch, curl-ups and $90^{\circ}$ push-ups. Differences by place of residence and types of housing were examined by correspondence analysis of two-dimensional tables with computing Chi square value at significance level $p<0.05$. Urban students performed higher level of flexibility, abdominal and upper strength and endurance than rural ones. Boys and girls living in a flat reached higher level of flexibility and abdominal strength/endurance however, they performed worse in upper strength and endurance than those living in a house. Slovak adolescents seem to have a healthier profile in abdominal muscular fitness and upper body flexibility than in lower body flexibility. The relationship between distribution of healthy fitness zone standards and residence area or housing type was revealed only in lower body flexibility, upper strength and endurance of urban and rural girls.
\end{abstract}

Keywords: HFZ standards, Rural \& urban, FITNESSGRAM, IPAQ

\section{Background}

Physical fitness is defined as the ability of body to function effectively, to enjoy leisure, to be healthy, to resist disease, and to cope with emergency situations. Physical fitness is used in two close meanings: health-related which state the health and well-being and skill-related which is more task-oriented based on the ability to perform specific aspects of sports or occupations (Hian et al. 2013).

Health-related components of physical fitness include body composition, cardiovascular fitness, flexibility, muscular endurance, and strength (Ganley et al. 2011). Agility, balance, coordination, power, reaction time, and speed are components of skill-related fitness (Hian et al. 2013).

The current emphasis in physical fitness has shifted from performance-related to health-related indicators.

\footnotetext{
*Correspondence: marta.gimunova@hotmail.com

${ }^{2}$ Faculty of Sport Studies, Masaryk University, Kamenice 5, 62500 Brno, Czech Republic

Full list of author information is available at the end of the article
}

Health-related physical fitness has been viewed as a narrower concept focusing on the aspects of fitness that are related to day-to-day functioning and health maintenance (Ujević et al. 2013).

Along with the modernization of the world, most of the technologies nowadays have made people less active because they want to do something with little input but bring out more output so people are making less of the physical work and this resulting in the decrement of fitness (Hian et al. 2013).

Appropriate physical activity is one of the main determinants of fitness (Gutin et al. 2005; Ruiz et al. 2006). Living in areas distinguished by population size can be associated with differences in eating habits, access to sport facilities and opportunities for physical activity. This environmental exposure might determine lifestyle behavior and it might be associated with fitness levels (De Vries et al. 2007; Roemmich et al. 2006; Parks et al. 2003).

However, it is not entirely clear whether such factors can affect aspects of body composition and, therefore, physical fitness (Tsimeas et al. 2005; Zvonař et al. 2010).

\section{Springer}

(c) 2015 Bebcakova et al. This article is distributed under the terms of the Creative Commons Attribution 4.0 International License (http://creativecommons.org/licenses/by/4.0/), which permits unrestricted use, distribution, and reproduction in any medium, provided you give appropriate credit to the original author(s) and the source, provide a link to the Creative Commons license, and indicate if changes were made. 
The distribution of health-related physical fitness across the population is not homogenous and has been found to differ, for example, according to gender, socioeconomic status and ethnicity, as well as area of residence (Brug et al. 2012).

Some studies examining differences in physical activity, physical fitness, and overweight among rural and urban children show that children from rural areas and small cities were more active than urban children (Joens-Matre et al. 2008).

However, contradictory reports have also been published in relation to physical fitness parameters in children living in urban and rural settings. In some cases, no differences have been identified in a range of fitness and motor skill measures between children from urban and rural areas (Krombholz 1997; Tsimeas et al. 2005).

Several authors reported that better living conditions have been shown to offer a potential advantage for improved physical fitness in urban compared with rural children (Rutenfranz et al. 1982; Reyes et al. 2003; Bathrellou et al. 2007).

On the contrary, urban residence has been linked to sedentary lifestyle due to lack of adequate space for play, concerns for safety, automatic transportation and computerization of many activities (Bathrellou et al. 2007).

Chillón et al (2011) reported that the differences between places of residence are country- and regionspecific, and data from different countries are required to better understand the relationship between place of residence and fitness in youth.

Researchers (Huang et al. 2010; Pratt et al. 1999; Sallis et al. 2000) have pointed out that much additional work is needed on geographical differences as compared with other social factors such as gender, race and ethnicity in studies of physical activity.

Moreover, most experts suggest that targeted interventions for specific subpopulations are needed to successfully increase physical activity (Baranowski et al. 2003). Thus, examining specific subpopulations within a social ecological approach is clearly needed (Joens-Matre et al. 2008).

The trend of increasing obesity observed in youth is often paralleled by a stabilization or even decrease of physical fitness and capacity. This has prompted various national and international organizations to promote programs counteracting the motor and health degradation of youths (Wilczewski et al. 1996).

Information about the regional distribution of health physical fitness status is necessary in order to tailor public health interventions, because a number of behavioral health risks are established in late childhood and early adolescence, including sedentary behavior and lack of strenuous exercise (Ujević et al. 2013).
Building on previous studies engaged in an issue of the distribution of healthy fitness zone standards we look for the answer to the question if there is the relationship between area of residence and achievement of HFZ in adolescents living in eastern part of Slovakia.

An answer to the question would enable us to monitor progressive or negative trend in the distribution of HFZ in adolescents. At the same time we would indirectly point out to the health quality of the population.

The purpose of the study was to analyze the relationship between the distribution of healthy fitness zone standards of high school students and type of housing (flat-house) or area of residence (urban-rural) in eastern part of Slovakia.

\section{Methods}

Present study is based on data collected by testing adolescents of 14 randomly selected high schools in rural and urban areas in eastern part of Slovakia. At each high school two classes were randomly selected for participating in this study. Fitness testing was carried out from October to November 2014.

\section{Participants}

Data on physical fitness were collected from 684 students attending randomly selected 14 high schools in Presov region (eastern part of Slovakia). Of these, 284 were boys $(41.52 \%)$ and 400 were girls $(58.48 \%)$. Mean age was $17.2 \pm 1.2$ years.

\section{Measures}

High school students were tested for abdominal strength and endurance using curl-up test, upper body strength and endurance using $90^{\circ}$ push up test, flexibility using shoulder stretch test and back-saver sit and reach test which are included in the FITNESSGRAM test battery (Plowman and Meredith 2013).

The FITNESSGRAM (Cooper Institute 2007) is in complex focused on testing health related physical fitness (body composition, aerobic fitness, muscle strength and endurance, flexibility) and motoric tests which are part of it are reliable enough for individual diagnostics (Suchomel 2004).

Demographic data on the location of residence (living in an urban or a rural area) and type of housing (house, flat) were obtained via IPAQ questionnaire (long version), which students completed online in the INDARES system.

The long version of the International Physical Activity Questionnaire (IPAQ) can be used internationally to obtain comparable estimates of PA. The questionnaire consists of six sections with specific questions: physical activity at school, physical activity during transport, 
physical activity in house/flat, physical activity in free time, time spent by sitting and demographic data. The questionnaire (IPAQ) has also been tested for reliability and validity and used in a number of international research projects (Craig et al. 2003). INDARES system consisted of several modules (questionnaires) related to physical activity (IPAQ, MPAM-R, WHO-5 etc.). Gained data were collected within extensive research conducted by the Center for Kinanthropology Research of Faculty of Physical Culture in Olomouc, Czech Republic.

The translation of IPAQ questionnaire to Slovak language was carried out by two sport linguists using the method of back translation of English version. The Slovak translation was compared to Czech version which is standardised. Based on the Czech and Slovak language proximity and socio-cultural environment the standardisation of Slovak version was not carried out.

Definitions of urban and rural areas are inconsistent. They are based on variables such as distance from trading centers and cut off population sizes of 100,000, 50,000, and 10,000 inhabitants (Tsimeas et al. 2005).

In Slovakia, state specifies according to law what is considered to be a village (usually less than 2000 inhabitants) and what is a town (more than 2000 inhabitants). Participant who chose in the IPAQ questionnaire place to live with more than 2000 inhabitants was classified as one who lives in urban area and less than 2000 inhabitants as one who lives in rural area.

According to Slovak socio-demographic reality a flat (usually without gardens) as a type of housing is considered to be block of flats ' part in towns while houses (great majority of them with gardens) are usually part of towns` suburbs or villages.

Participant's legal representative (in the case when subject was younger than 18 years) or participants (in the case when subject was older than 18 years) received a verbal description of the study procedures before testing and completed a written informed consent. The study protocol was approved by the ethical committee of Masaryk University, Brno, Czech Republic. Measurements were taken according to the ethical standards of the Declaration of Helsinki (Harriss and Atkinson 2011).

\section{Data analyses}

For statistical processing was used correspondence analysis of two-dimensional tables with computing Chi square value. Two-dimensional tables include following parameters: urban-rural (pass-fail); flat-house (pass-fail). An alpha level of $p<0.05$ was used for all statistical tests.

\section{Results}

To interpret results and to answer the research question we used summary tables in which data about housing type (flat, house) and residence area (urban, rural) of participants are presented. The influence of social factor on the distribution of healthy fitness zone (HFZ) standards was categorized in a dichotomous way (pass-fail) in four tests physical fitness test (PFT) of FITNESSGRAM. Chi square test was used to determine the significance of relationships between the distribution of HFZ standards and residence area or housing type.

\section{Curl-up test}

Results of the curl-up test are presented in Tables 1 and 2 for boys and girls, respectively. Of all participants, 100 urban boys (35.7 \%) and 89 rural boys (31.8 \%) met the standard (see Tables 1,2). Results based on Chi square test showed that the distribution of HFZ standards did not correlate with an area of residence or type of housing. Regarding the fact that the number of boys and girls living in a town and in a village differed (same goes for living in a flat or a house), we evaluated collected data individually for urban (boys from town and girls from town) and rural areas (boys from village and girls from village) and analogically for living in a flat (boys from flat and girls from flat) and living in a house (boys living in house and girls living in house). These results are presented in Figs. 1 and 2 for all evaluated tests.

The results showed that in $66.2 \%$ of urban boys and $69 \%$ of rural boys met HFZ standards for the curl-up test. Minimal differences in meeting HFZ standards were observed between boys living in a flat $(68.5 \%)$ and those living in a house (66\%).

Slightly bigger differences were found between urban and rural girls than in boys. In total, 130 urban girls (32.7\% of all participants) and 133 rural girls (33.4 \% of all participants) met HFZ standards (see Tables 1, 2). Similarly to boys, results in the girls group showed that the distribution of HFZ standards did not correlate with an area of residence or type of housing.

Complete evaluation of HFZ standards distribution within urban and rural girls and girls living in a flat or a house is presented in Fig. 2. We found that $69.1 \%$ of girls living in urban areas, $63.3 \%$ of girls living in rural areas, $67.8 \%$ of girls living in a flat and $65.3 \%$ of girls living in a house met HFZ standards.

\section{Push-Up test}

Results of the Push-Up test are presented in Tables 1 and 2 for both boys and girls, respectively. Of all participants, 141 boys living in urban areas (50.1\%) and 120 boys living in rural areas (42.7 \%) reached HFZ standards. Similarly to previous results, statistical analysis revealed that the distribution of HFZ standards did not correlate with an area of residence or type of housing. 
Table 1 Distribution of healthy fitness zone standards of boys in tests of FITNESSGRAM according to the type of residence and housing

\begin{tabular}{|c|c|c|c|c|c|c|c|c|c|c|}
\hline \multirow[t]{2}{*}{ Test } & \multirow[t]{2}{*}{$n$} & \multicolumn{4}{|c|}{ Urban } & \multicolumn{4}{|l|}{ Rural } & \multirow[t]{2}{*}{ Chi square test } \\
\hline & & Pass & $\%$ & Fail & $\%$ & Pass & $\%$ & Fail & $\%$ & \\
\hline Curl-up & 280 & 100 & 35.7 & 51 & 18.2 & 89 & 31.8 & 40 & 14.3 & 0.2428 \\
\hline Push-up & 281 & 141 & 50.1 & 12 & 4.3 & 120 & 42.7 & 8 & 2.8 & 0.2675 \\
\hline BSR & 283 & 47 & 16.6 & 107 & 37.8 & 34 & 12 & 95 & 33.6 & 0.5954 \\
\hline S-stretch & 282 & 139 & 49.3 & 15 & 5.3 & 110 & 39 & 18 & 6.4 & 1.2638 \\
\hline \multirow[t]{2}{*}{ Test } & \multirow[t]{2}{*}{$n$} & \multicolumn{4}{|l|}{ Flat } & \multicolumn{4}{|c|}{ House } & \multirow[t]{2}{*}{ Chi square test } \\
\hline & & Pass & $\%$ & Fail & $\%$ & Pass & $\%$ & Fail & $\%$ & \\
\hline Curl-up & 277 & 87 & 31.4 & 40 & 14.4 & 99 & 35.7 & 51 & 18.4 & 0.1954 \\
\hline Push-up & 278 & 115 & 41.4 & 13 & 4.7 & 143 & 51.4 & 7 & 2.5 & 3.1172 \\
\hline BSR & 280 & 42 & 15 & 87 & 31.1 & 38 & 13.6 & 113 & 40.3 & 1.8629 \\
\hline S-stretch & 279 & 117 & 41.9 & 12 & 4.3 & 129 & 46.2 & 21 & 7.5 & 1.4675 \\
\hline
\end{tabular}

$n$ number of participants; \% percentages; BSR back-saver sit and reach; S-Stretch shoulder stretched

Table 2 Distribution of healthy fitness zone standards of girls in tests of FITNESSGRAM according to the type of residence and housing

\begin{tabular}{|c|c|c|c|c|c|c|c|c|c|c|}
\hline \multirow[t]{2}{*}{ Test } & \multirow[t]{2}{*}{$\mathbf{n}$} & \multicolumn{4}{|c|}{ Urban } & \multicolumn{4}{|c|}{ Rural } & \multirow[t]{2}{*}{ Chi square test } \\
\hline & & Pass & $\%$ & Fail & $\%$ & Pass & $\%$ & Fail & $\%$ & \\
\hline Curl-Up & 398 & 130 & 32.7 & 58 & 14.6 & 133 & 33.4 & 77 & 19.3 & 1.4967 \\
\hline Push-Up & 400 & 105 & 26.2 & 84 & 21.0 & 101 & 25.3 & 110 & 27.5 & $2.3593^{*}$ \\
\hline $\mathrm{BSR}$ & 322 & 41 & 12.7 & 110 & 34.2 & 22 & 6.8 & 149 & 46.3 & $10.4006^{* *}$ \\
\hline S-Stretch & 319 & 146 & 45.8 & 5 & 1.6 & 157 & 49.2 & 11 & 3.4 & 1.7483 \\
\hline \multirow[t]{2}{*}{ Test } & \multirow[t]{2}{*}{$\mathrm{n}$} & \multicolumn{4}{|l|}{ Flat } & \multicolumn{4}{|c|}{ House } & \multirow[t]{2}{*}{ Chi square test } \\
\hline & & Pass & $\%$ & Fail & $\%$ & Pass & $\%$ & Fail & $\%$ & \\
\hline Curl-Up & 397 & 101 & 25.4 & 48 & 12.1 & 162 & 40.8 & 86 & 21.7 & 0.2524 \\
\hline Push-Up & 399 & 71 & 17.8 & 78 & 19.5 & 134 & 33.6 & 116 & 29.1 & 1.3226 \\
\hline $\mathrm{BSR}$ & 326 & 31 & 9.5 & 90 & 27.6 & 33 & 10.1 & 172 & 52.8 & $4.3727^{*}$ \\
\hline S-Stretch & 323 & 112 & 34.6 & 8 & 2.5 & 196 & 60.7 & 7 & 2.2 & 1.7640 \\
\hline
\end{tabular}

$n$ number of participants; \% percentages; ${ }^{*}$ significant relationship $p<0.05,{ }^{* *}$ significant relationship $p<0.01 ; B S R$ back-saver sit and reach, S-Stretch shoulder stretched

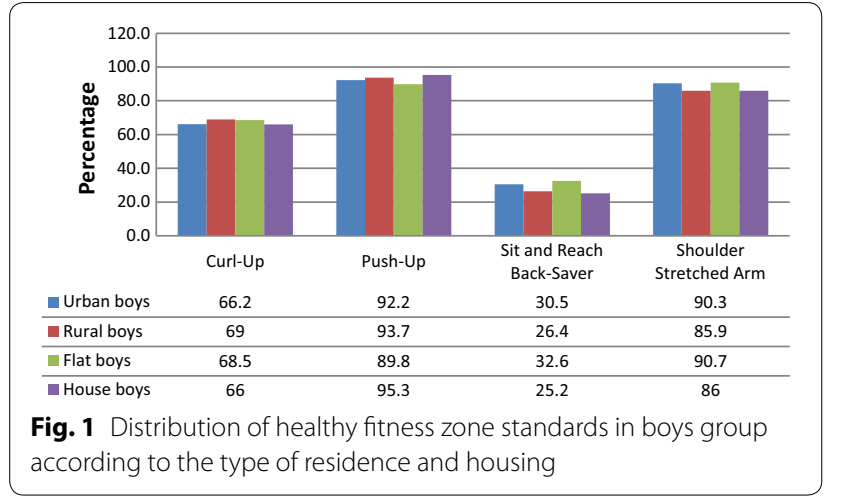

Complete evaluation of HFZ standards distribution for urban and rural boys and boys living in a flat or a house is presented in Fig. 1 together with other tests. Results of Push-Up test revealed that $92.2 \%$ of urban boys and $93.7 \%$ of rural boys met HFZ standards. According to the type of housing, $89.8 \%$ of boys living in a flat and $95.3 \%$ of boys living in a house reached HFZ standards. Boys showed high level of abdominal strength and endurance, which was confirmed by best results in Push-Up test of all four tests.

In contrast to boys, girls performed much worse than males. Only 105 urban girls (26.2\% of all participants) 
and 101 rural girls (25.3\% of all participants) met HFZ standards (see Tables 1,2). Concerning the type of housing, $71(17.8 \%)$ girls living in a flat and 134 (33.6\%) girls living in a house reached HFZ standards.

Results of girls showed that the distribution of HFZ standards correlated with an area of residence $(p<0.05)$ in favor of urban girls. No correlation was found between the distribution of HFZ standards and type of housing.

Complete evaluation of HFZ standards distribution of urban and rural girls and girls living in a flat or a house is presented in Fig. 2. The results showed that $55.6 \%$ of urban girls, $47.9 \%$ of rural girls, $47.7 \%$ of girls living in a flat and $53.6 \%$ of girls living in a house met HFZ standards.

Whereas boys performed the best results in Push-Up test, girls achieved the second worst results in the test.

\section{Back-saver sit and reach test}

Results of Push-Up test are presented in Tables 1 and 2 for boys and girls, respectively. Of all participants, 47 urban boys (16.6\%) and 34 rural boys (12\%) reached HFZ standards. In term of housing, 42 (15 \%) boys living in a flat and $22(6.8 \%)$ boys living in a house met HFZ standards. Once again, the distribution of HFZ standards in boys group did not correlate with an area of residence or type of housing in back-saver sit and reach test.

Complete evaluation of HFZ standards distribution for urban and rural boys and boys living in a flat or a house is presented in Fig. 1 together with other tests. Results for back-saver sit and reach test showed that $30.5 \%$ of urban, only $26.4 \%$ of rural boys, $32.6 \%$ of boys living in a flat and $25.2 \%$ of boys living in a house met HFZ standards. Boys had very low level of flexibility and performed the worst in this flexibility test.

In back-saver sit and reach test, girls performed worse than boys. Only 41 urban girls (12.7 \%) and 22 rural girls (6.8\%) of all participants reached HFZ standards (see Tables 1, 2). Regarding to the type of housing, 31 girls living in a flat (9.5\%) and 33 girls living in a house (10.1\%) met standards.

Results of girls showed that the distribution of HFZ standards correlated with an area of residence $(p<0.01)$ for urban girls group and with type of housing $(p<0.05)$ for girls living in a flat.

Complete evaluation of HFZ standards distribution for urban and rural girls and girls living in flat or house is presented in Fig. 2. The results showed that $27.2 \%$ of urban girls, only $12.9 \%$ of rural girls, $25.6 \%$ of girls living in a flat and $16.1 \%$ of girls living in a house met HFZ standards.

\section{Shoulder stretch test}

Results of shoulder stretch test are presented in Tables 1 and 2. Of all participants, 110 urban boys (49.3\%) and

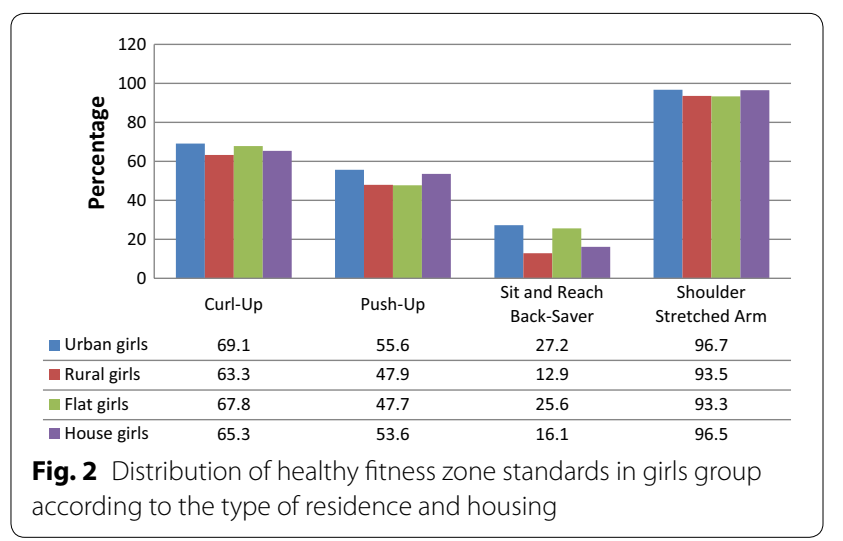

110 rural boys (39 \%) reached HFZ standards. Regarding to the type of housing, 117 (41.9 \%) boys living in a flat 129 (46.2 \%) boys living in a house reached the HFZ standards. The distribution of HFZ standards in boys did not correlate with an area of residence or type of housing in back-saver sit and reach test.

Complete evaluation of HFZ standards distribution for urban and rural boys and boys living in flat or house is presented in Fig. 1 together with other tests. Results of shoulder stretch test revealed that $90.3 \%$ of urban boys and $85.9 \%$ of rural boys met HFZ standards. According to the type of housing, $90.7 \%$ of boys living in a flat and $86 \%$ of boys living in a house reached HFZ standards. Whereas the results of the first test measuring flexibility (back-saver sit and reach test) indicate very low level of flexibility, results in shoulder stretch test revealed contradictory findings.

Girls performed worse than boys in shoulder stretch test. Of all participants, 146 urban girls (45.8\%) and 157 rural girls (49.2\%) of all participants reached HFZ standards (see Tables 1, 2). Concerning the type of housing, 112 girls living in a flat (34.6\%) and 196 girls living in a house $(60.7 \%)$ met HFZ standards. No relationship was found between the distribution of HFZ standards and type of housing and area of residence.

Complete evaluation of HFZ standards distribution for urban and rural girls and girls living in flat or house is presented in Fig. 2. We found that $96.7 \%$ of urban girls, $93.5 \%$ of rural girls, $93.3 \%$ of girls living in a flat and $96.5 \%$ of girls living in a house reached HFZ standards. Within shoulder stretch test girls group performed the best results of all four tests.

\section{Discussion}

Results point to minor differences in the level of abdominal strength and endurance between urban and rural students and students living in a flat or a house. Urban students performed better than those living in a rural 
area $(1.5 \%)$ as well as students living in a flat than students living in a house (2.5\%). Statistical analysis showed that there is no relationship between the distribution of HFZ standards and residence area or housing type in both males and females.

Minor differences in results are contrary to the results reported by Petroski et al. (2012) who found that adolescents from rural areas presented at almost 10 times higher chance of inadequate muscle strength/endurance than those from urban areas. Also, a study by Andrade et al. (2014) and Chillón et al. 2011) showed that with respect to residential location, urban adolescents had significantly higher mean score curl-ups $(p<0.01)$ than rural ones.

For upper body strength and endurance, urban students showed higher achievement rate percentage than rural students ( $3.1 \%$ distinction). On the contrary, students living in a flat showed higher level upper body strength and endurance compared with students living in a flat (5.7\% distinction). Statistical analysis proved that the distribution of HFZ standards depends on type of housing only in females.

Urban adolescents showed higher level of flexibility than their rural counterparts (distinction in sit and reach back-saver test was 9.2 and $3.8 \%$ in shoulder stretched arm test). Moreover, students living in a flat were more flexible than students living in a house (difference in sit and reach back-saver test was $8.45 \%$ and only $0.75 \%$ in shoulder stretched arm test). Apart from back-saver sit and reach test in which the relationship between the distribution of HFZ and type of housing and residence area was found, no other relationship was observed.

Study by Petroski et al. (2012) showed that with respect to flexibility, adolescents from urban areas presented a $56 \%$ higher chance of inadequate flexibility than schoolchildren from rural areas. Similarly, Chillón et al. (2011) noted that rural young people had lower flexibility $(p<0.001)$ compared with their urban peers.

Generally, there are lots of studies around the world presenting contradictory results by comparing fitness levels of urban and rural children and adolescence. Tsimeas et al. (2005) have found that US urban children have superior fitness levels compare to those living in rural areas, whereas a report from Poland (Wilczewski et al. 1996) proposed that rural children were fitter than their urban counterparts. Chillón et al. (2011) presented results in which rural Spanish children and adolescents had overall a healthier profile than their urban peers in terms of upper- and lower-body muscular fitness, while they performed worse in speed-agility and flexibility.

One of the reasons for such discrepancy may be found in focusing on physical activity habits of urban and rural students in relation to the HFZ standards distribution. Huang et al. (2010) found no substantial differences in the physical activity habits and sedentary behaviors among students living in urban and rural areas where urban children reported more physical activity after school, on holidays and weekends, and also in total amount of physical activity compared with the rural children. Hence, public health awareness directed to enhance physical activity and decrease sedentary lifestyle among youngsters should focus equally to urban and rural children (Bathrellou et al. 2007).

Determining gender differences in the distribution of HFZ standards for abdominal strength and endurance has shown contradictory findings. Boys living in rural areas achieved higher level of percentage of HFZ standards distribution than girls (5.7 \% difference). Girls living in a house or flat had lower success rate percentage of HFZ standards distribution than boys $(0.7 \%$ distinction for house or flat). Only girls living in urban areas were more successful in the HFZ standards distribution than boys ( $2.9 \%$ distinction).

For the test which is a criterion of upper body strength and endurance most distinctive gender differences were found. Boys who live in urban and rural areas performed better than girls. Gender difference in urban areas was 36.6 and $45.8 \%$ in rural areas. Similarly, girls living in a flat or house achieved worse scores than boys ( $42.1 \%$ difference for flat and $41.7 \%$ for house).

Similar results were reported by Andrade et al. (2014) in their study where boys showed significantly higher levels of strength and endurance and balance compared with girls.

Gender differences in flexibility present divergent results. In sit and reach back-saver test, boys who live in urban and rural area were better than girls (distinction $3.3 \%$ in urban a $13.5 \%$ in rural area). Similarly, boys living in a flat or a house performed better than girls (7 \% distinction in flat and $9.1 \%$ in a house). In shoulder stretch test, we observed better flexibility of upper body in favor of girls who live in urban and rural area (distinction $6.4 \%$ in urban and $7.6 \%$ in rural area) as well as in favor of girls living in a flat or a house (2.6\% difference for flat and $10.5 \%$ for house). Andrade et al. (2014) reported findings contrary to our results as they found that boys showed significantly lower levels of the sit and reach test $(p<0.01)$.

Reyes et al. (2003) found that urban children of both sexes performed better in timed sit-ups and boys showed somewhat greater flexibility in the lower back and upper thighs (sit and reach) than girls. The differences in flexibility between urban and rural girls and urban and rural boys were not significant, which is similar to our results. 
Renfrow et al. (2011) found that gender differences may be attributed to the difference of sport choice between boys and girls, especially in a private school setting.

What we should consider is the fact that only two thirds of students regardless of housing type or residence area (on average $66.9 \%$ ) reached an acceptable level of abdominal strength and endurance, which determines correct body posture.

Percentage success rate in the distribution of HFZ indicates that boys, regardless of housing type and residence area, showed on average $92.75 \%$ achievement in the level of upper body strength and endurance. Girls did not meet standards and less than half of them (on average $51.2 \%$ ) achieved an acceptable level of upper body strength and endurance. Progressive muscle weaknesses in upper body may reflect in health quality and cause several muscle imbalances and disorders like upper crossed syndrome.

There were some discrepancies within the distribution of HFZ standards in flexibility tests. Adolescents performed significantly the worst results in back-saver sit and reach test (on average $28.68 \%$ in boys and $20.45 \%$ in girls) while in shoulder stretch test girls achieved the best results (on average $95 \%$ ) and boys the second best results (88.23\%).

Similarly, Dórea et al. (2008) found that only $51 \%$ of the boys and $58 \%$ of the girls in the sit-and-reach test reached the established criteria. Low level of flexibility in lower-limb area is negative predisposition for quality of life considering frequent occurrence of lower crossed syndrome.

There was on average $36 \%$ of cases when girls and boys did not reach the HFZ standards in our study. Study of Powell et al. (2009) showed that $23 \%$ did not meet the standard for muscular strength, endurance, and flexibility.

In conclusion, urban students performed better in majority of fitness tests than their counterparts living in rural areas. Similarly, Hian et al. (2013) observed that there were more urban students who had better score of physical fitness compared with the rural samples. It also could be related to Eiben et al. (2005) who noted that the urban boys and girls produced better physical performance than their rural counterparts. This may be caused by several factors reported by Loucaides et al. (2004) who found that equipment availability and transportations were better in urban than rural areas. Schools in urban areas also had better facilities such as field, track and others if compared with rural schools (Hian et al. 2013).

Physical fitness level in childhood and adolescence is positively associated with present and future healthrelated outcomes such as risk for obesity, cardiovascular disease, skeletal health and mental health (Ortega et al. 2008). Therefore, it is inevitable that a health-related physical education curriculum can provide students with substantially more physical activity during physical education classes. Sallis et al. (1997) point to the fact that improved physical education classes can potentially benefit $97 \%$ of elementary school students.

The environment might have little influence on several health-related factors, since residence area and housing type differences were small for majority of tests. It is important to note that the place of residence and appropriate external motivation should be taken into account when implementing effective interventions to promote physical activity and health.

\section{Conclusions}

Slovak adolescents seem to have a healthier profile in abdominal muscular fitness and upper body flexibility than in lower body flexibility. Boys performed better in all tests than girls apart from upper body flexibility.

Boys and girls from urban areas had higher level of flexibility, abdominal and upper strength and endurance than their rural counterparts. Those living in a flat reached higher level of flexibility and abdominal strength/endurance; however, they performed worse in upper strength and endurance than boys and girls living in a house.

The relationship between the distribution of HFZ standards and residence area or housing type was found only in lower body flexibility of girls and upper body strength and endurance of urban and rural girls.

\section{Abbreviations \\ HFZ: healthy fitness zone; IPAQ: International Physical Activity Questionnaire; PFT: physical fitness test.}

\section{Authors' contributions}

VB conceived of the study, study design and coordination. BV carried out collecting data and participant coordination. PK helped with collecting data and to draft the manuscript. JJ participated in the design of the study and performed the statistical analysis. IB participated in collecting data. MZ participated in establishing the study design and coordination. MG helped to draft the manuscript. All authors read and approved the final manuscript.

\section{Author details}

1 Faculty of Sports, University of Presov, UI. 17. novembra 13, 08116 Prešov, Slovak Republic. ${ }^{2}$ Faculty of Sport Studies, Masaryk University, Kamenice 5, 62500 Brno, Czech Republic.

\section{Acknowledgements}

The paper was supported by Slovak Research and Development Agency on the basis of agreement no. APVV-0768-11.

\section{Competing interests}

The authors declare that they have no competing interests.

Received: 7 September 2015 Accepted: 28 October 2015

Published online: 10 November 2015 


\section{References}

Andrade S, Ochoa-Avilés A, Lachat C, Escobar P, Verstraeten R, Van Camp J et al (2014) Physical fitness among urban and rural Ecuadorian adolescents and its association with blood lipids: a cross sectional study. BMC Pediatr 14(106):1-11

Baranowski T, Cullen KW, Nicklas T, Thompson D, Baranowski J (2003) Are current health behavioral change models helpful in guiding prevention of weight gain efforts? Obes Res 11:23-34

Bathrellou E, Lazarou CH, Panagiotakos DB, Sidossis LS (2007) Physical activity patterns and sedentary behaviors of children from urban and rural areas of Cyprus. Cent Eur J Public Health 15(2):66-70

Brug J, van Stralen MM, Chinapaw MJ, De Bourdeaudhuij I, Lien N, Bere E et al (2012) Differences in weight status and energy-balance related behaviors according to ethnic background among adolescents in seven countries in Europe: the ENERGY-project. Pediatr Obes 7:399-411

Chillón P, Ortega FB, Ferrando JA, Casajus JA (2011) Physical fitness in rural and urban children and adolescents from Spain. J Sci Med Sport 14:417-423

Craig CL, Marshall AL, Sjostrom M, Bauman AE, Booth ML, Ainsworth BE et al (2003) International physical activity questionnaire: 12 country reliability and validity. Med Sci Sports Exerc 35:1381-1395

De Vries SI, Bakker I, Van Mechelen W, Hopman-Rock M (2007) Determinants of activity friendly neighborhoods for children: results from the SPACE study. Am J Health Promot 21(4):312-316

Dórea V, Ronque ERV, Cyrino ES, Serassuelo JRH, Gobbo LA, Carvalho FO et al (2008) Health-related physical fitness in students from Jequié, BA, Brazil. Revista Brasileira de Medicina do Esporte 14(6):494-499

Eiben OG, Barabás A, Németh Á (2005) Comparison of growth, maturation, and physical fitness of Hungarian urban and rural boys and girls. J Hum Ecol 17(2):93-100

Ganley KJ, Paterno MV, Miles C, Stout J, Brawner L, Girolami G et al (2011) Health-related fitness in children and adolescents. Pediatr Phys Ther 23(3):208-220

Gutin B, Yin Z, Humphries MC, Barbeau P (2005) Relations of moderate and vigorous physical activity to fitness and fatness in adolescents. Am J Clin Nutr 81(4):746-750

Harriss DJ, Atkinson G (2011) Update-Ethical Standards in Sport and Exercise Science Research International. J Sports Med 32(11):819-821

Hian TCH, Mahmud ZF, Choong TY (2013) Physical fitness level between urban and rural students-case study. Procedia Soc Behav Sci 90:847-852

Huang S, Hung W, Sharpe PA, Wai JP (2010) Neighborhood environment and physical activity among Urban and Rural schoolchildren in Taiwan. Health Place 16:470-476

Institute Cooper (2007) FITNESSGRAM/ACTIVITYGRAM. Test administration manual, 4th edn. Human Kinetics, Champain

Joens-Matre RR, Welk GJ, Calabro MA, Russell DW, Nicklay E, Hensley LD (2008) Rural-urban differences in physical activity, physical fitness, and overweight prevalence of children. J Rural Health 24(1):49-54

Krombholz H (1997) Physical performance in relation to age, sex, social class and sports activities in kindergarten and elementary school. Percept Mot Skills 84:1168-1170

Loucaides CA, Chedzoy SM, Bennett N (2004) Differences in physical activity levels between urban and rural school children in Cyprus. Health Educ Res 19(2):138-147

Ortega FB, Ruiz JR, Castillo MJ, Sjostrom M (2008) Physical fitness in childhood and adolescence: a powerful marker of health. Int J Obes 32(1):1-11
Parks SE, Housemann RA, Brownson RC (2003) Differential correlates of physical activity in urban and rural adults of various socioeconomic backgrounds in the United States. J Epidemiol Community Health 57(1):29-35

Petroski EL, Da Silva AF, Rodrigues AB, Pelegrini A (2012) Association between low levels of physical fitness and sociodemographic factors in adolescents from rural and urban areas. Motricidade 8(1):5-13

Plowman SA, Meredith MD (2013) Fitnessgram/activitygram reference guide, 4th edn. The Cooper Institute, Dallas

Powell KE, Roberts AM, Ross JG, Phillips MAC, Ujamaa DA, Zhou M (2009) Low physical fitness among fifth- and seventh-grade students, Georgia, 2006 Am J Prev Med 36(4):304-310

Pratt M, Macera C, Blanaton C (1999) Levels of physical activity and inactivity in children and adults in the United States: current evidence and research issues. Med Sci Sports Exerc 68:241-248

Renfrow MS, Caputo JL, Otto SM, Farley RR, Eveland-Sayers BM (2011) The relationship between sports participation and health-related physical fitness in middle school and high school students. Phys Educ 68(3):118-123

Reyes ME, Tan SK, Malina RM (2003) Urban-rural contrasts in the growth status of school children in Oaxaca, Mexico. Ann Hum Biol 30(6):693-713

Roemmich JN, Epstein LH, Raja S, Yin L, Robinson J, Winiewicz D (2006) Influence of access to parks and recreational facilities on the physical activity of young youth. Prev Med 43(6):437-441

Ruiz J, Ortega F, Gutierrez A, Meusel D, Sjöström M, Castillo M (2006) Healthrelated fitness assessment in childhood and adolescence: a European approach based on the AVENA, EYHS and HELENA studies. J Publ Health 14:269-277

Rutenfranz J, Andersen KL, Seliger V, Masironi R (1982) Health standards in terms of exercise fitness of school children in urban and rural areas in various European countries. Ann Clin Res 14(34):33-36

Sallis JF, McKenzie TL, Alcaraz JE, Kolody B, Faucette N, Hovell MF (1997) The effects of a 2-year physical education program (SPARK) on physical activity and fitness in elementary school students Sports, Play and Active Recreation for Kids. Am J Publ Health 87(8):1328-1334

Sallis JF, Prochaska J, Taylor W (2000) A review of correlates of physical activity of children and adolescents. Med Sci Sports Exerc 32:963-975

Suchomel A (2004) Príspevek ke standardizaci vybraných motorických testú batérie FITNESSGRAM. In: Suchomel A, Wolf M (eds) Telesná výchova a šport, Liberec - Euroregion Nisa. Liberec: Technická univerzita, 2004

Tsimeas PD, Tsiokanos AL, Koutedakis Y, Tsigilis N, Kellis S (2005) Does living in urban or rural settings affect aspects of physical fitness in children? An allometric approach. Br J Sports Med 39:671-674

Ujević T, Sporiš G, Milanović Z, Pantelić S, Neljak B (2013) Differences between health-related physical fitness profiles of Croatian children in urban and rural areas. Coll Antropol 37(1):75-80

Wilczewski A, Krawczyk B, Skład M, Saczuk J, Majle B (1996) Physical development and fitness of children from urban and rural areas as determined by EUROFIT test battery. Biol Sport Wars 13:113-126

Zvonař M, Korvas P, Nykodým J et al (2010) Movement and health aspects in kinantropological research. Masarykova Univerzita, Brno

\section{Submit your manuscript to a SpringerOpen ${ }^{\circ}$ journal and benefit from:}

- Convenient online submission

- Rigorous peer review

- Immediate publication on acceptance

- Open access: articles freely available online

- High visibility within the field

- Retaining the copyright to your article

Submit your next manuscript at $>$ springeropen.com 